\title{
Mathematical modelling of the continuous casting of blooms and beam blanks
}

\section{Daniela Fátima Gomes* (iD), Bernardo Martins Braga (iD), Roberto Parreiras Tavares (iD, Maurício Covcevich Bagatini}

Metallurgical and Materials Engineering Department, School of Engineering, Federal University of Minas Gerais, Av. Presidente Antônio Carlos 6627, 31270-901 Belo Horizonte, Brazil.

\begin{abstract}
Defects and discontinuities generated in continuous casting are directly related to heat transfer during the process and the stresses to which the material is subjected. Knowledge of these phenomena is essential for both process safety and the quality of the final product. The aim of this work is to analyze the thermo-mechanical behavior of blooms and beam blanks during continuous casting. The continuous casting machine considered in this study is used to cast both blooms and beam blanks. The secondary cooling can be divided into cooling zone z0, cooling zone z1, cooling zone z2, and cooling zone z3. For each geometry, there are specific molds, z0, z1, z2 (sprays and support rollers), which need to be replaced when there is a geometry shift. The changing of the cooling segments brings security risks for the operators and reduces the continuous casting availability. Therefore, it is desired to have a common $\mathrm{z} 2$ for both blooms and beam blanks to reduce operational risk exposure and increase the machine production rate. For this to be possible, it is necessary to assess the temperature and resistance of the solidified skin, the effects of thermal stresses, ferrostatic pressure, and contact stresses. This work is the first step in this study. A thermo-mechanical model was developed for both geometries. The thermal model was verified by temperature measurement and shell measurements of blackouts. Finally, the results were analyzed and compared.
\end{abstract}

Keywords: continuous casting, mathematical modeling, beam blanks and blooms

\section{Introduction}

The continuous casting process is the most frequently used method to obtain as-cast products in the steel industry. The high productivity and potential to obtain different shapes are some of the advantages of this technique (Bobadilla et al., 1993; Thomas, 2002; Vynnycky, 2018). During this process, liquid steel is poured from a ladle to a tundish and then flows from the tundish to a copper mold which is cooled by water running in the interior of its walls.
The material starts to solidify in the mold and, as it moves forward, the semi-solid as-cast enters the secondary cooling zone. There, a set of sprays sprinkles water onto its skin, creating a forced convection flow that accelerates the cooling process. By the time the material reaches the end of the machine, the solidification is complete, and the as-cast can be cut by the oxygen cutting machine.

During this process, the steel is supported by rolls that guide its trajectory until the transportation table. The position and size of the rolls are chosen to balance

\footnotetext{
* Corresponding author: danielafg05@gmail.com ORCID ID's: 0000-0002-0965-3847 (Fátima Gomes D.), 0000-0003-0634-5416 (Braga Martins B.), 0000-0001-9348-2181 (Parreiras Tavares R.), 0000-0002-3986-9833 (Covcevich Bagatini M.) (C) 2021 Authors. This is an open access publication, which can be used, distributed and reproduced in any medium according to the Creative Commons CC-BY 4.0 License requiring that the original work has been properly cited.
} 
the mechanical forces and avoid geometry distortions that might lead to defects later in the process.

To model this process, many aspects need to be taken into consideration (Lee et al., 2000; Mahapatra et al., 1991; Schmidt \& Josefsson, 1974). The heat transfer, the phase change (liquid to solid) and the mechanical deformations due to the thermal tensions, ferrostatic pressure, contact between solid layer and foot rolls, and distortions in the as-cast because of the machine radius.

The relevant process parameters for these phenomena are steel superheat, water flow and pressure around the mold and in the spray nozzles, the casting powder, the casting speed, and the machine set up. The use of inappropriate process parameter values can cause breakouts, shape defects, and the formation of cracks.

The continuous casting machine considered in this study is used to cast both blooms and beam blanks. For each geometry, there are specific mold and secondary cooling setups (sprays and support rollers) which need to be replaced when there is a geometry shift. The changing of the cooling segments brings security risks for the operators and reduces the continuous casting availability. Therefore, it is desirable to reduce the need to exchange at least one of the segments. For this to be possible, it is necessary to know the phenomena involved and verify the interferences in the quality of the as-cast products.

This paper describes the development of an integrated mathematical model of the heat transfer, solidification and, thermal tensions for the continuous casting process of blooms and beam blanks. The results of the computational simulations are discussed, and the particularities of each geometry analyzed.

\section{Methodology}

In this section a brief description of the casting machine will be presented, along with the numerical procedure, considerations made in the development of the models, boundary conditions, physical equations, steel physical properties, and the experiments for temperature measurement of the strand. Commercial software ANSYS CFX 17.1 and ANSYS 17.1 Mechanical were used to solve the thermal and mechanical equations.

\subsection{Description of the machine}

The present work was developed considering a continuous casting machine of blooms and beam blanks. This machine has four strands, and it can produce blooms of
$300 \mathrm{~mm} \times 450 \mathrm{~mm}$ and $300 \mathrm{~mm} \times 350 \mathrm{~mm}$ and beam blanks of $400 \mathrm{~mm} \times 480 \mathrm{~mm} \times 120 \mathrm{~mm}$.

The primary cooling takes place in the mold, and secondary cooling takes place in the spray chamber which has four control zones ( $\mathrm{z} 0$ to $\mathrm{z} 3$ ). Zones $\mathrm{z} 0$ to z2 are different for blooms and beam blanks and are changeable. Zone $\mathrm{z} 0$ is part of the mold set and contains the first set of sprays and rollers, Zone $\mathrm{z} 3$ is a common set up. In zones $\mathrm{z} 0$ and $\mathrm{z} 3$ there are water sprays, in zones z1 and z2, there are air mist sprays. Currently, Zone z3 remains inactive. After the spray chamber, blooms or beam blanks are straightened and cut. A representation of the machine, with the length of each control zone, can be seen in Figure 1.

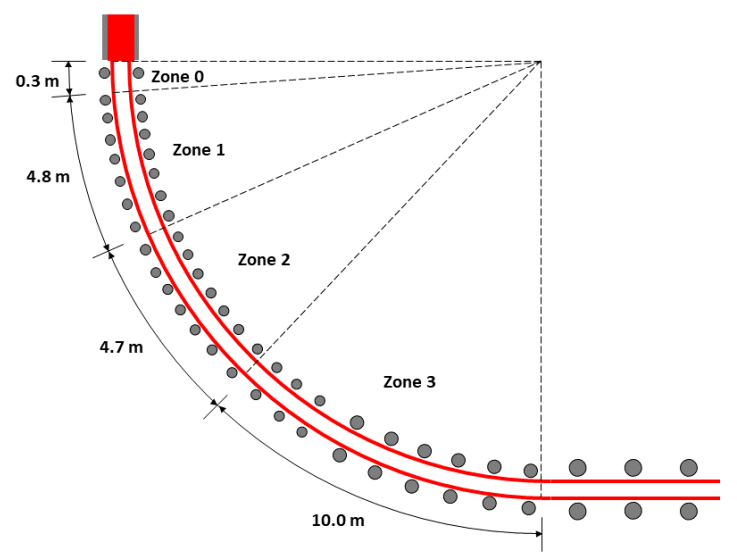

Fig 1. Continuous casting machine schematic

\subsection{Heat transfer and the solidification model}

A two-dimensional mathematical model of heat transfer, solidification, and thermal tensions of the blooms and beam blanks was developed. The main assumptions are listed below:

- heat transfer in the casting direction was neglected due to the high Peclet number;

- the latent heat of steel solidification was converted into an equivalent specific heat capacity in the mushy zone;

- the density and emissivity of the steel was considered constant whereas the heat capacity, thermal conductivity, were considered temperature-dependent;

- the effects of strand shrinkage were neglected;

the convective heat flow in the liquid pool and the mushy zone was accounted for the effective thermal conductivity (Ma et al., 2008). 
The thermal model was based on the general energy equation during the unsteady state, as described in Equation (1):

$$
\rho \frac{C_{p}^{e q} \partial(T)}{\partial t}=\frac{\partial}{\partial x}\left(k_{e f} \frac{\partial T}{\partial x}\right)+\frac{\partial}{\partial y}\left(k_{e f} \frac{\partial T}{\partial y}\right)+S
$$

where: $t$ - the time of simulation $[\mathrm{s}] ; T$ - the temperature $\left[{ }^{\circ} \mathrm{C}\right] ; k_{e f}-$ the thermal conductivity $\left[\mathrm{W} \cdot \mathrm{m}^{-1} \cdot{ }^{\circ} \mathrm{C}^{-1}\right]$; $c_{p}^{e q}$ - the equivalent heat capacity of steel $\left[\mathrm{J} \cdot \mathrm{kg}^{-1} \cdot \mathrm{K}^{-1}\right]$; $\rho$ - the density of steel $\left[\mathrm{kg} \cdot \mathrm{m}^{-3}\right] ; x, y$ - the direction of the coordinate system, along the transversal section [m].

\subsection{Mechanical model}

The structural mechanical model was developed in three dimensions for a one meter long as-cast piece. The simulations presented in this work were carried out for the zone z2 region, which is the zone where there is an interest in using a common segment for blooms and beam blanks. The main assumptions are listed below:

- the as-cast bloom and beam blank were considered flexible and the rollers rigid as it was interested in evaluating the deformations and stresses in those continuous casting geometries;

- unsteady state phenomena;

- friction contact between the rollers and the as-cast pieces;

- free rotation rollers.

The thermo-elastic-plastic material model, with bilinear isotropic hardening, was used to calculate the strain and stress distributions, which are important to provide information about the as-cast product quality, especially the occurrence of cracks. The total value of the deformation vector was calculated using Equation (2), according to the Von Misses criteria as used by (Chen et al., 2009; Liu et al., 2017; Zeng et al., 2020). The influence of the ferrostatic pressure was also be taken into consideration.

$$
\{\varepsilon\}=\left\{\varepsilon^{e l}\right\}+\left\{\varepsilon^{p l}\right\}+\left\{\varepsilon^{t h}\right\}
$$

where: $\varepsilon$ - total deformation $[\%] ; \varepsilon^{e l}-$ incremental elastic strain component [\%]; $\varepsilon^{p l}-$ incremental plastic strain component $[\%] ; \varepsilon^{\text {th }}-$ incremental thermal strain component $[\%]$.

The stress is related to the elastic strain by:

$$
\{\sigma\}=[D]\left\{\varepsilon^{e l}\right\}
$$

where: $\{\sigma\}$ - the stress vector; $[D]-$ the elasticity or elastic stiffness matrix or stress-strain matrix.

$$
\begin{gathered}
\left\{\varepsilon^{e l}\right\}=\{\varepsilon\}-\left\{\varepsilon^{\text {th }}\right\}-\left\{\varepsilon^{p l}\right\} \\
\{\varepsilon\}=\left\{\varepsilon^{\text {th }}\right\}+\left\{\varepsilon^{p l}\right\}+\left[D^{-1}\right]\{\sigma\}
\end{gathered}
$$

where: $\{\varepsilon\}-$ the total strain vector; $\left\{\varepsilon^{p l}\right\}-$ plastic strain vector; $\left\{\varepsilon^{\text {th }}\right\}$ - the thermal strain vector; $\left\{\varepsilon^{t h}\right\}=\Delta T\left[\begin{array}{cccccc}\alpha_{x}^{s e} & \alpha_{y}^{s e} & \alpha_{z}^{s e} & 0 & 0 & 0\end{array}\right]^{T}$.

$$
[D]^{-1}=\left[\begin{array}{cccccc}
\frac{1}{E_{x}} & -\frac{v_{x y}}{E_{x}} & -\frac{v_{x z}}{E_{x}} & 0 & 0 & 0 \\
-\frac{v_{y x}}{E_{y}} & \frac{1}{E_{y}} & -\frac{v_{y z}}{E_{y}} & 0 & 0 & 0 \\
-\frac{v_{z x}}{E_{z}} & -\frac{v_{z y}}{E_{z}} & \frac{1}{E_{z}} & 0 & 0 & 0 \\
0 & 0 & 0 & \frac{1}{G_{x y}} & 0 & 0 \\
0 & 0 & 0 & 0 & \frac{1}{G_{y z}} & 0 \\
0 & 0 & 0 & 0 & 0 & \frac{1}{G_{x z}}
\end{array}\right]
$$

where: $\alpha_{x}^{s e}$ is the secant coefficient of thermal expansion in the $x$ direction.

$$
\Delta T=T-T_{r e f}
$$

where: $T$ - the temperature in the point in question; $T_{\text {ref }}$ - reference (strain-free) temperature (input).

\subsection{Initial and boundary conditions}

To obtain the solution for the differential equations, it is necessary to define the initial and boundary conditions. The temperature value in the mold was adopted as the initial condition.

$$
T=T_{0}
$$

$T_{0}$ is the temperature of the liquid steel entering the mold. This temperature was assumed to be $1560^{\circ} \mathrm{C}$. The heat flux is specified in the mold region. The heat flux in primary cooling can be calculated using Equation (9), described by Ji et al. (2016), Lee et al. (1998), X. Qin et al. (2019), and Assunção et al. (2014).

$$
q=268000-227 \sqrt{\frac{L_{m}}{v}}
$$

where: $L_{m}$ - effective length of mold [m]; $v$ - casting speed $\left[\mathrm{m} \cdot \mathrm{min}^{-1}\right] ; q-$ heat flux at the surface of the mold $\left[\mathrm{W} \cdot \mathrm{m}^{-2}\right]$. 
In the secondary cooling zone, heat is transferred mostly due to convection and radiation, due to the high temperature values of the strand. The heat flow in the spray region was be calculated using equations (10) and (11):

$$
\begin{gathered}
q=h_{\text {spray }}\left(T_{s}-T_{w}\right) \\
h_{\text {spray }}=a W^{b}
\end{gathered}
$$

where: $h_{\text {spray }}$ - heat transfer coefficient in the spray cooling $\left[\mathrm{W} \cdot \mathrm{m}^{-2} \cdot{ }^{\circ} \mathrm{C}^{-1}\right] ; T_{s}$ - temperature in the as-cast surface $\left[{ }^{\circ} \mathrm{C}\right]$; $W$ - water flow rate $\left[\mathrm{L} \cdot \mathrm{m}^{-2} \cdot \mathrm{min}^{-1}\right] ; a, b$ - empirical constants dependent on the type of the spray nozzles. For air mist spray nozzle: $a=0.336, b=0.724$. For the water spray nozzle: $a=0.25, b=0.64$. Those values were provided by the spray fabricant SMS group. Each spray was considered as an individual heat extraction source in the model developed.

The radiation heat flow zone was be calculated by Equation (12):

$$
q=\sigma \varepsilon\left(T_{s}^{4}-T_{e}^{4}\right)
$$

where: $\sigma$-Stefan-Boltzmann constant; $\varepsilon$ - emissivity; $T_{e}$ - temperature of the environment $\left[{ }^{\circ} \mathrm{C}\right]$.

The ferrostatic pressure exerted by the liquid portion inside the geometry is one of the forces that generate tension in the walls and can cause deformations. This pressure was calculated using the Equation (13):

$$
P_{f}=\rho_{\text {steel }} g H
$$

where: $P_{f}-$ the ferrostatic pressure $[\mathrm{Pa}] ; \rho_{\text {steel }}-$ the steel density $\left[\mathrm{kg} \cdot \mathrm{m}^{-3}\right] ; g-$ the acceleration due to gravity $\left[\mathrm{m} \cdot \mathrm{s}^{-2}\right] ; H-$ the distance from the meniscus $[\mathrm{m}]$.

To calculate this pressure, the as-cast geometry was considered as a solidified shell with a thickness equal to that calculated by the thermal model. The temperature profile was also imported from the thermal model. The interior is filled with liquid steel but to simulate the phenomenon of liquid pressure on the walls, this interior was considered as a void where the inner walls suffer a force in the axial direction. The strain free temperature is considered equal to solidus temperature.

$$
T_{\text {ref }}=T_{\text {solidus }}=1481^{\circ} \mathrm{C}
$$

Both thermal and mechanical calculations are made by the Ansys software using the FEM method.

\subsection{Physical properties of steel}

The physical properties of the steel have a great influence on the predictions of the model and therefore must be carefully chosen to guarantee the accuracy of the solution. The properties considered in the simulations are shown in Table 1.

\subsection{Experimental procedures}

To verify the predictions of the models, experiments were carried out in the industrial plant to verify the surface temperature and the thickness of the solidified layer.

The surface temperatures of the blocks and beam blanks were measured using a FLIR model FLIR E75 thermographic camera. The same method was used by (Ji et al., 2014) to validate a thermomechanical model for the soft reduction of a bloom. As the spray chamber is closed, measurements were taken after the straightener, where there are no sprays or water steam, and images can be taken with good resolution.

Table 1. Physical properties

\begin{tabular}{|l|c|}
\hline \multicolumn{1}{|c|}{ Parameter } & Value \\
\hline Density $\left[\mathrm{kg} \cdot \mathrm{m}^{-3}\right]$ (Lee et al., 2000) & 7020 \\
\hline Latent heat of the solidification $\left[\mathrm{J} \cdot \mathrm{kg}^{-1}\right]$ (Lee et al., 2000) & 272,000 \\
\hline Solidus temperature $\left[{ }^{\circ} \mathrm{C}\right]$ & 1481 \\
\hline Liquidus temperature $\left[{ }^{\circ} \mathrm{C}\right]$ & 1513 \\
\hline Specific heat $\left[\mathrm{J} \cdot \mathrm{kg}^{-1}\right](\mathrm{Wang}$ et al., 2005) & $481.48 \cdot 0.19 \cdot T_{\text {steel }}$ \\
\hline Thermal conductivity $\left[\mathrm{W} \cdot \mathrm{m}^{-1} \cdot \mathrm{K}^{-1}\right]($ Thomas, 1995) & $15.9+0.11 \cdot T_{\text {steel }}$ \\
\hline Emissivity $(\mathrm{Lee}$ et al., 2000$)$ & 0.8 \\
\hline Young Modulus $[\mathrm{GPa}](\mathrm{Kozlowski}$ et al., 1992) & $968-2.33 \cdot T_{\text {steel }}+1.9 \cdot 10^{-3} \cdot T_{\text {steel }}{ }^{2}-5.18 \cdot 10^{-7} \cdot T_{\text {steel }}{ }^{3}$ \\
\hline Poisson ratio & 0.3 \\
\hline Friction coefficient $(\mathrm{Q}$. Qin et al., 2014) & 0.01 \\
\hline Yield strength limit $[\mathrm{Pa}]$ & $6.62 \cdot 10^{6}$ \\
\hline Shear modulus $[\mathrm{Pa}]$ & $4.6154 \cdot 10^{9}$ \\
\hline
\end{tabular}


The shell thickness was obtained by analyzing breakouts shells that occurred during operational problems in the casting of blooms and beam blanks. Figure 2 shows the occurrences of such incidents.
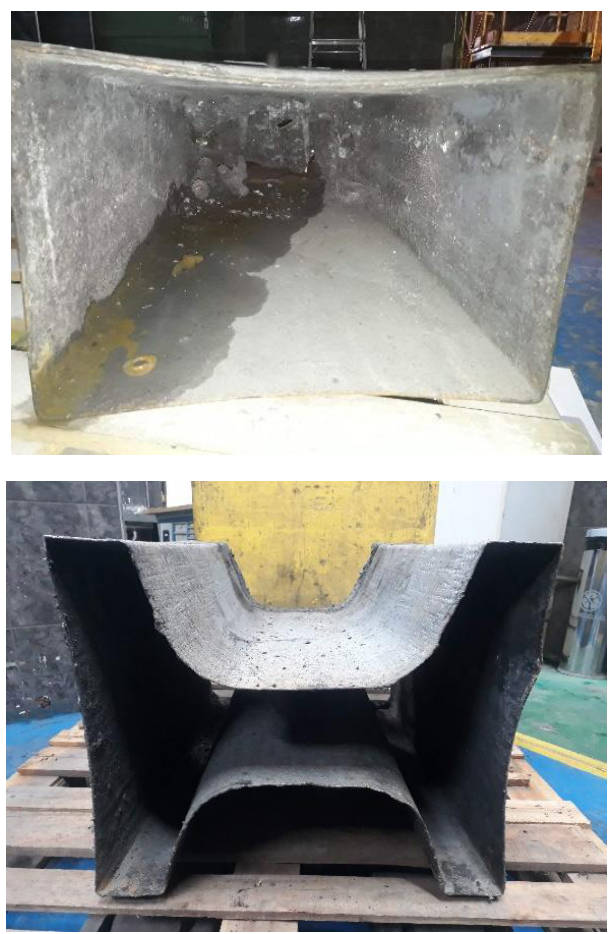

Fig. 2: Solid shell off a bloom and beam blank

The thickness of the solidified layer was measured using a caliper. The measurements were made both down the mold narrow face and around the perimeter. The plant's supervisory system allows the collection of process parameters at the time of the occurrence of blackouts. Thus, to compare the measured data with the results of the models, the same parameters from the moment of the blackout were used. Skin breakages occur due to situations where the skin loses strength and which are not the ideal process, however the remaining skin can be used to validate heat transfer models (Meng \& Thomas, 2003).

\section{Results and discussion}

In this chapter, the results of surface temperature, solid shell thickness, and stress due to the ferrostatic pressure, calculated by the computational model, will be presented.

In the simulations shown, ASTM A502 steel (structural steel) was considered. This is the most frequently produced product and allows the collection of a considerable amount of experimental data. The casting conditions used in the simulations in this section are shown in Table 3.
Table 3. Casting conditions

\begin{tabular}{|l|c|c|}
\hline \multicolumn{1}{|c|}{ Variable } & Bloom & $\begin{array}{c}\text { Beam } \\
\text { blank }\end{array}$ \\
\hline Casting speed $\left[\mathrm{m} \cdot \mathrm{min}^{-1}\right]$ & 0.9 & 0.9 \\
\hline Mold wide face water flow $\left[\mathrm{L} \cdot \mathrm{min}^{-1}\right]$ & 1260.0 & 1620.0 \\
\hline $\begin{array}{l}\text { Mold narrow face water flow } \\
{\left[\mathrm{L} \cdot \mathrm{min}^{-1}\right]}\end{array}$ & 720.0 & 820.0 \\
\hline Superheat temperature $\left[{ }^{\circ} \mathrm{C}\right]$ & 30.0 & 35.0 \\
\hline $\mathrm{Z}$ total water flow $\left[\mathrm{L} \cdot \mathrm{min}^{-1}\right]$ & 85.0 & 143.0 \\
\hline Z1 total water flow $\left[\mathrm{L} \cdot \mathrm{min}^{-1}\right]$ & 420.0 & 649.0 \\
\hline Z2 total water flow $\left[\mathrm{L} \cdot \mathrm{min}^{-1}\right]$ & 168.0 & 255.0 \\
\hline
\end{tabular}

\subsection{Temperature profiles}

Figure 3 shows the locations and values of the temperatures of the bloom as a function of the distance to the meniscus. The results of the experimental measurements are also included in the figure and demonstrate the good agreement of the predictions and the experimental data. Figure 4 depicts similar results for the simulation of the casting of the beam blank.

(B)
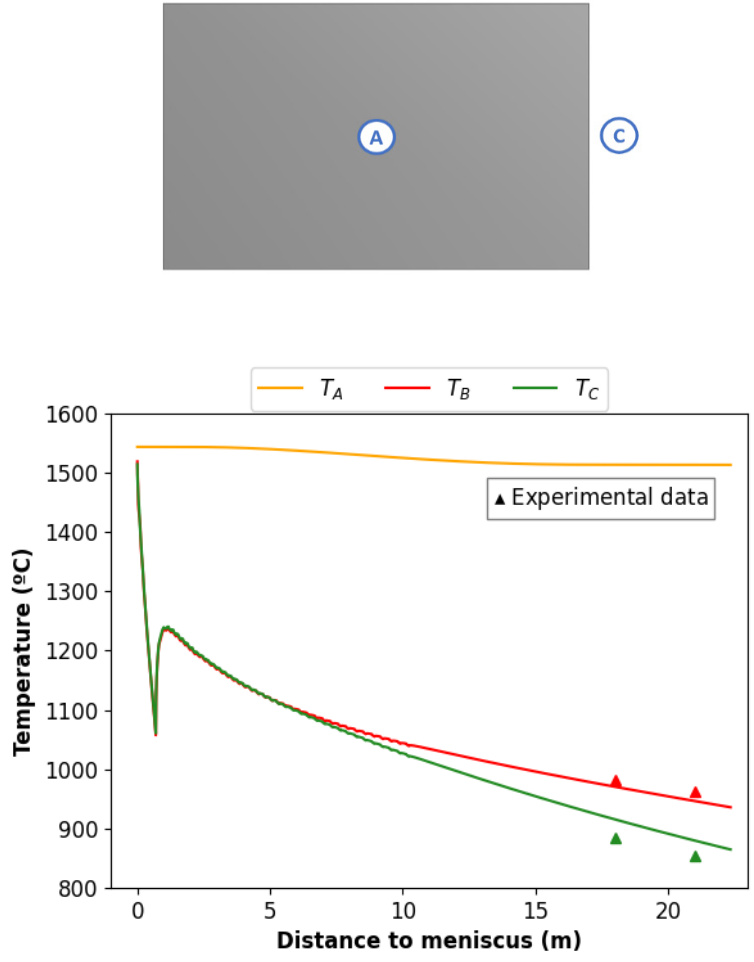

Fig. 3. Bloom temperature profiles

The temperatures profiles are very similar to those found in the literature (Assunção et al., 2014; Ohba et al., 2008). The model was able to predict the temperature 
values in the wide face (B) and the narrow face (C), with an error of $1.5 \%$ and $3.3 \%$, respectively. In the case of the wide face, the model predicts a lower temperature than the measurement with the thermographic camera. The measurement in this position has difficulties because it is not possible to be positioned exactly on the side of the as-cast ingot. This factor may have contributed to this difference. An improved analysis of radiation in the case of the beam blank will be implemented in the future.

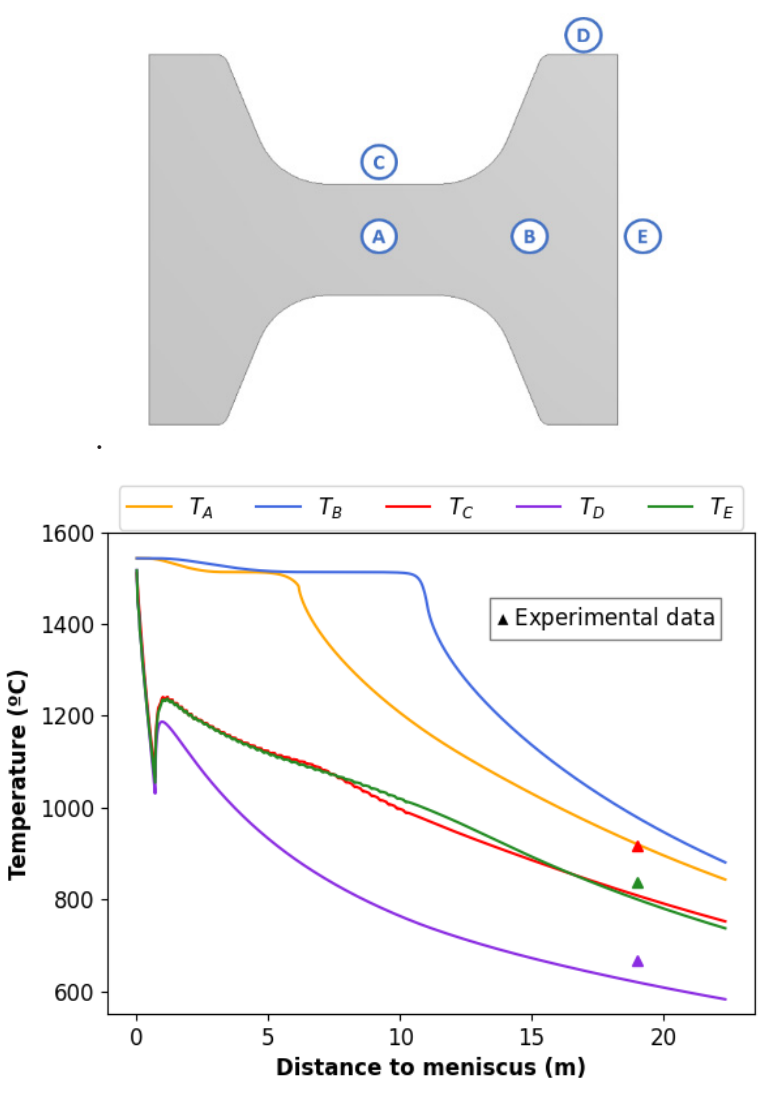

Fig. 4. Beam blank temperature profiles

Due to the more complex geometry of the beam blank, the temperature profiles are shown in a higher number of positions to improve the analysis. Similar to the bloom, the temperature profiles are similar results identified in the literature (Hibbeler et al., 2009; Lee et al., 1998; Xu et al., 2010). The model predicted temperatures in positions $\mathrm{C}, \mathrm{D}$, and $\mathrm{E}$ with errors of $11.6 \%, 6.9 \%$, and $4.5 \%$, respectively. The beam blank model was less accurate than the bloom model, especially for the $\mathrm{C}$ point.

In addition to the measurement difficulties, some considerations made in the present work regarding the casting of blooms are not entirely valid for a more complex geometry such as beam blanks, particularly the uniform distribution of water sprays and radiation between the curved region of the beam blank.

\subsection{Solid shell}

Figure 5 shows the solid shell thickness calculated by the computational model at the wide and narrow faces of the bloom and in the flange and web of the beam blank. The shell thickness calculated by the model was compared to the values obtained by measuring the pieces remaining from breakouts. Breakouts occurred at the beginning of the casting when conditions are different from the continuous process. However, there was a good concordance between the order of magnitude of the measured and calculated shell thickness.
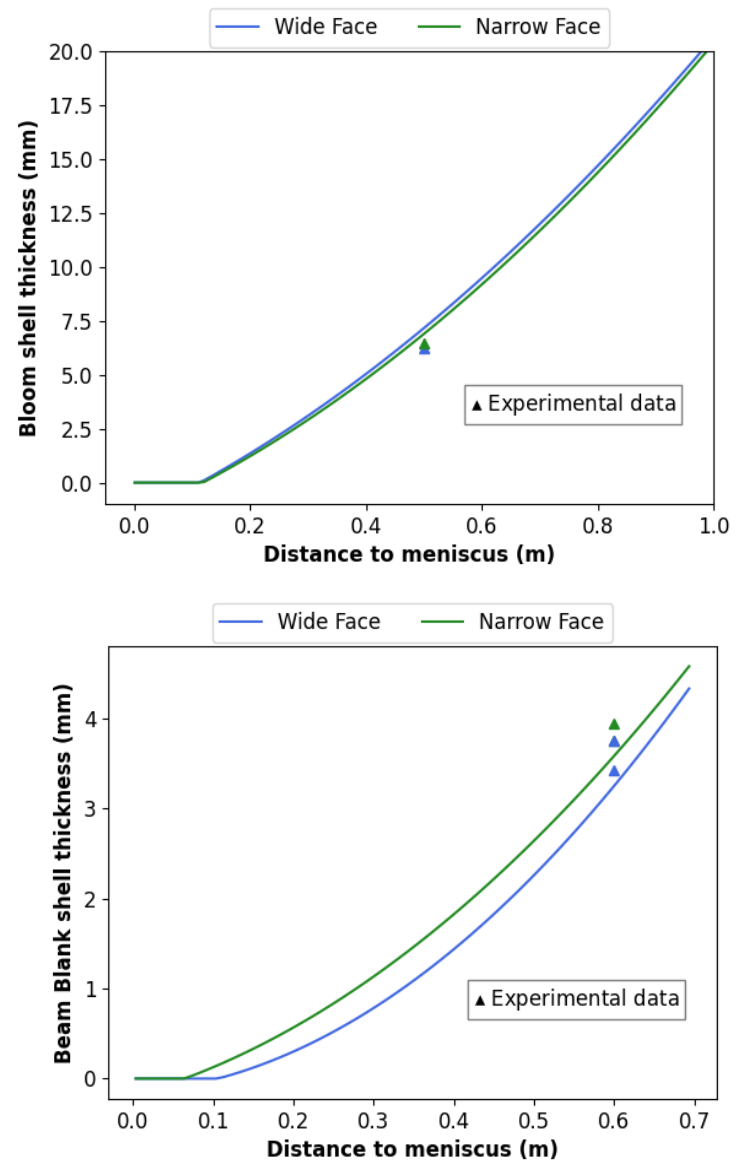

Fig. 5. Bloom and beam blank solid shell thickness

The model calculated the skin and obtained the following percentage errors: Bloom wide face $14.4 \%$, Bloom narrow face $6.2 \%$, Beam blank wide face $9.2 \%$, Beam blank narrow face $7.0 \%$

\subsection{Stress calculations}

One of the objectives of this work is to evaluate the possibility of using a common zone 2 for blooms and beam blanks. Thus, it is necessary to know the solidified shell 
thickness along this zone and the stresses involved considering the current assembly. Figure 6 illustrates the solidified shell of blooms and beam blanks in the current setup.
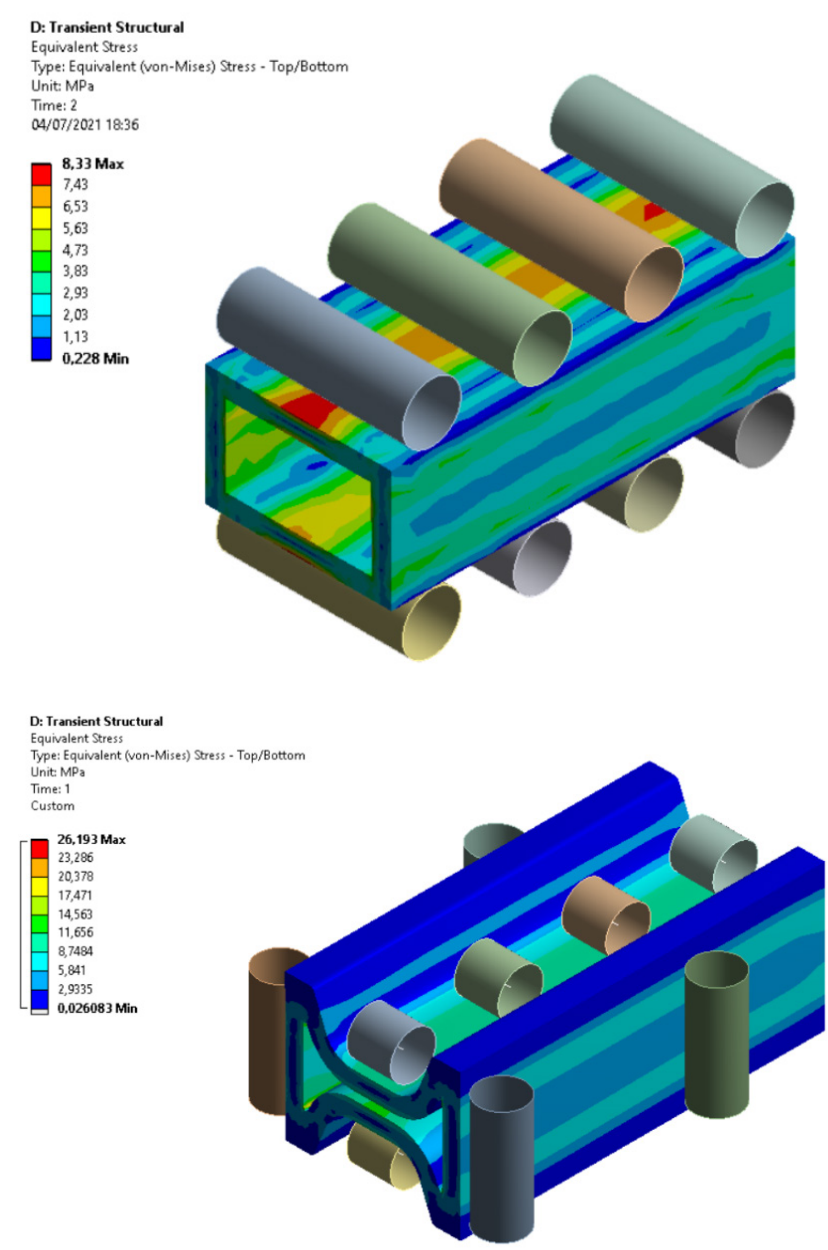

Fig. 6. Bloom and beam blank stress at the beginning of the secondary cooling zone

When observing the figures, it can be seen that the beam blank reaches higher stress values than the bloom. This is expected due to the complexity of the geometry. The highest value of stress observed in the beam blank occurs at the corner. The bloom has stress values around $4 \mathrm{MPa}$ and the beam blank around 5.5 MPa. Values close to the material yield stress limit even below it. Both geometries have regions where the stress was greater than the yield point. However, this is a small portion of the as-cast volume. A mechanical model was developed and permitted the analysis of the stresses involved in the casting process of blooms and beam blanks.

\section{Conclusions}

This paper describes the temperature profile and solid shell thickness of blooms and beam blanks. Some conclusions are:

- The model for the bloom could predict the temperature values in the wide face (B) and the narrow face $(\mathrm{C})$, with an error of $1.5 \%$ and $3.3 \%$. In the case of the wide face, the model is predicting a lower temperature than the measurement with the thermographic camera.

- The model for the beam blank predicted temperatures in positions $\mathrm{C}, \mathrm{D}$, and $\mathrm{E}$ with errors of $11.6 \%, 6.9 \%$, and $4.5 \%$, respectively. The beam blank model was less accurate than the bloom model, especially for the $\mathrm{C}$ point.

- The beam blank cools faster than the bloom for the same casting conditions.

- Some considerations made in this work do not affect a simple geometry as the bloom in the same way but can affect a more complex geometry such as beam blanks. For example, the uniform distribution of water sprays and radiation between the curved region of the beam blank.

- A mechanical model was developed and allowed to analyze the stresses involved in the casting process of blooms and beam blanks and the stress values in the cooling zone analyzed can reach the yield stress limit.

\section{References}

Assunção, C.S., Tavares, R.P., \& Oliveira, G.D. (2014). Water distribution assessment applied to mathematical model of continuous casting of steel. Associação Brasileira de Metalurgia, Materiais e Mineração (ABM), 3, 2895-2905. https://doi. org/10.5151/1982-9345-26252.

Bobadilla, M., Jolivet, J.M., Lamant, J.Y., \& Larrecq, M. (1993). Continuous casting of steel: a close connection between solidification studies and industrial process development. Materials Science and Engineering A, 173(1-2), 275-285. https:// doi.org/10.1016/0921-5093(93)90229-8.

Chen, W., Zhang, Y.Z., Zhang, C.J., Zhu, L.G., Lu, W.G., Wang, B.X., \& Ma, J.H. (2009). Thermo-mechanical simulation and parameters optimization for beam blank continuous casting. Materials Science and Engineering A, 499(1-2), 58-63. https://doi.org/10.1016/j.msea.2007.11.116.

Hibbeler, L.C., Xu, K., Thomas, B.G., Koric, S., \& Spangler, C. (2009). Thermomechanical Modeling of Beam Blank Casting. Iron and Steel Technology, 6(7), 60-73. 
Ji, C., Luo, S., \& Zhu, M. (2014). Analysis and application of soft reduction amount for bloom continuous casting process. ISIJ International, 54(3), 504-510. https://doi.org/10.2355/isijinternational.54.504.

Ji, C., Wu, C., \& Zhu, M. (2016). Thermo-Mechanical Behavior of the Continuous Casting Bloom in the Heavy Reduction Process. JOM, 68(12), 3107-3115. https://doi.org/10.1007/s11837-016-2041-8.

Kozlowski, P.F., Thomas, B.G., Azzi, J.A., \& Wang, H. (1992). Simple constitutive equations for steel at high temperature. Metallurgical Transactions A, 23(3), 903-918. https://doi.org/10.1007/BF02675567.

Lee, J.-E., Yoon, J.-K., \& Han, H.N. (1998). 3-Dimensional Mathematical Model for the Analysis of Continuous Beam Blank Casting Using Body Fitted Coordinate System. ISIJ International, 38(2), 132-141. https://doi.org/10.2355/isijinternational.38.132.

Lee, J.-E., Yeo, T.-J., OH, K.H., Yoon, J.-K., \& Yoon, U.-S. (2000). Prediction of cracks in continuously cast steel beam blank through fully coupled analysis of fluid flow, heat transfer, and deformation behavior of a solidifying shell. Metallurgical and Materials Transactions A: Physical Metallurgy and Materials Science, 31(1), 225-237. https://doi.org/10.1007/ s11661-000-0067-5.

Liu, Y., Liu, X., Fu, H., Lou, M., \& Xie, J. (2017). Effects of process parameters on surface quality, composition segregation, microstructure and properties of QSn6. 5-0. 1 alloy slabs fabricated by HCCM horizontal continuous casting. Journal of Iron and Steel Research International, 24(3), 273-281. https://doi.org/10.1016/S1006-706X(17)30040-7.

Ma, J., Xie, Z., \& Jia, G. (2008). Applying of Real-time Heat Transfer and Solidification Model on the Dynamic Control System of Billet Continuous Casting. ISIJ International, 48(12), 1722-1727. https://doi.org/10.2355/isijinternational.48.1722.

Mahapatra, R.B., Brimacombe, J.K., \& Samarasekera, I.V. (1991). Mold behavior and its influence on quality in the continuous casting of steel slabs: Part II. Mold heat transfer, mold flux behavior, formation of oscillation marks, longitudinal off-corner depressions, and subsurface cracks. Metallurgical Transactions B, 22(6), 875-888. https://doi.org/10.1007/ BF02651164.

Meng, Y., \& Thomas, B.G. (2003). Modeling Transient Slag-Layer Phenomena in the Shell/mold Gap in Continuous Casting of Steel. Metallurgical and Materials Transactions B: Process Metallurgy and Materials Processing Science, 34(5), 707-725. https://doi.org/10.1007/s11663-003-0041-x.

Ohba, Y., Kitade, S., \& Takasu, I. (2008). Austenite grain refining of as-cast bloom surface by reduction of oscillation mark depth. ISIJ International, 3(3), 3-8. https://doi.org/10.2355/isijinternational.48.350.

Qin, Q., Shang, S., Wu, D., \& Zang, Y. (2014). Comparative analysis of bulge deformation between 2D and 3D finite element models. Advances in Mechanical Engineering, 6. https://doi.org/10.1155/2014/942719.

Qin, X., Cheng, C., Li, Y., Zhang, C., Zhang, J., \& Jin, Y. (2019). A simulation study on the flow behavior of liquid steel in tundish with annular argon blowing in the upper nozzle. Metals, 9(2). https://doi.org/10.3390/met9020225.

Schmidt, L., \& Josefsson, A. (1974). On the Formation and Avoidance of Transverse Cracks in Continuously Cast Slabs From Curved Mould Machines. Scandinavian Journal of Metallurgy, 3(5), 193-199.

Thomas, B.G. (1995). Issues in Thermal-Mechanical Modeling of Casting Processes. ISIJ International, 35(6), $737-743$. https://doi.org/10.2355/isijinternational.35.737.

Thomas, B.G. (2002). Modeling of the continuous casting of steel - Past, present, and future. Metallurgical and Materials Transactions B: Process Metallurgy and Materials Processing Science, 33(6), 795-812. https://doi.org/10.1007/s11663002-0063-9.

Vynnycky, M. (2018). Applied mathematical modelling of continuous casting processes: A review. Metals, 8(11). https://doi. org/10.3390/met8110928.

Wang, H., Li, G., Lei, Y., Zhao, Y., Dai, Q., \& Wang, J. (2005). Mathematical Heat Transfer Model Research for the Improvement of Continuous Casting Slab Temperature. ISIJ International, 45(9), 1291-1296. https://doi.org/10.2355/isijinternational.45.1291.

Xu, H.L., Wen, G.H., Sun, W., Wang, K.Z., \& Yan, B. (2010). Analysis of Thermal Behavior for Beam Blank Continuous Casting Mold. Journal of Iron and Steel Research International, 17(12), 17-22. https://doi.org/10.1016/S1006-706X(10)60191-4.

Zeng, J., Gan, M., Yan, X., Wang, Q., \& He, S. (2020). Mathematical Modeling of Heat Transfer and Deformation of Bloom Tube Mold in Continuous Casting Process. Metallurgical and Materials Transactions B: Process Metallurgy and Materials Processing Science, 51(1), 213-221. https://doi.org/10.1007/s11663-019-01738-2. 